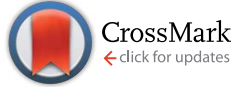

Cite this: RSC Adv., 2015, 5, 45291

Received 2nd March 2015 Accepted 12th May 2015

DOI: $10.1039 / \mathrm{c} 5 \mathrm{ra03683f}$

www.rsc.org/advances

\title{
Contactless bottom-up electrodeposition of nickel for 3D integrated circuits
}

\author{
Mingrui Zhao, ${ }^{\text {a }}$ Rajesh Balachandran, ${ }^{\text {b } Z a c h ~ P a t t e r s o n, ~}{ }^{\mathrm{c}}$ Roman Gouk, ${ }^{\mathrm{c}}$ \\ Steven Verhaverbeke, ${ }^{C}$ Farhang Shadman ${ }^{a}$ and Manish Keswani*b
}

Packaging applications in the semiconductor industry rely on electrodepositing metals into high aspect ratio (HAR) vias without the formation of any defects or voids. The process and economic efficiency of conventional methodologies are limited by the ability to achieve high deposition rates along with uniformity of the deposited metal layer. In this work, a contactless and scalable electrodeposition technique has been developed to deposit metallic nickel onto p-doped silicon wafers. The effect of various process variables such as deposition and etchant solution composition and concentration, solution temperature and stirring on nickel deposition rates have been investigated. The importance of backside silicon oxidation and subsequent oxide etching on the kinetics of nickel deposition on frontside silicon has been highlighted.

\section{Introduction}

Electrodeposition is the most common industrial technique for forming "back end of line" (BEOL) electrical connections for integrated circuits as well as for filling of through silicon vias (TSVs) in 3D packaging. ${ }^{\mathbf{1 - 4}}$ In conventional electrodeposition systems, ions in solution $\left(\right.$ e.g. $\left.\mathrm{Cu}^{2+}, \mathrm{Ni}^{2+}\right)$ are reduced to their metallic form by an applied current through a cathode. The circuit is completed by means of using a sacrificial anode which is typically made of the same metal that is being deposited and dissolves proportionally as the metal is deposited. The metal deposits into patterned recesses on a wafer surface to create an array of electrical interconnections. Electrodeposition replaced blanket deposition and patterning techniques that were used for metallization when aluminium was prominent before $1998 .^{5}$ Copper is currently the most common metal in back end metallization. However, copper must be isolated from bulk silicon and dielectric materials by a diffusion barrier to prevent poisoning. ${ }^{6}$ Semiconductor grade silicon is so sensitive to copper poisoning that nearly all fabrication centers have noncopper dedicated areas in which nothing that has contacted copper is permitted. Nickel has a lower conductivity than copper, but does not require a diffusion barrier to prevent poisoning of the substrate and exhibits a similar electroplating efficiency. ${ }^{7}$ In this publication, a recently developed contactless electrodeposition technique ${ }^{8}$ is used to deposit bulk metallic

${ }^{a}$ Chemical and Environmental Engineering, University of Arizona, Tucson, AZ, USA ${ }^{b}$ Materials Science and Engineering, University of Arizona, 1235 E. James E. Rogers Way, Tucson, AZ 85721, USA. E-mail: manishk@email.arizona.edu; Fax: +1-520621-8059

${ }^{c}$ Applied Materials, Inc., Santa Clara, CA, USA nickel and accompanying factors that affect the rate of deposition are discussed.

Conventional methods of depositing nickel include the use of acidic solutions containing either sulfates or chlorides of nickel., ${ }^{7-13}$ Nickel is known to deposit by the following mechanism as shown in Table 1 (where $\mathrm{X}^{-}$denotes $\mathrm{OH}^{-}$or $\mathrm{Cl}^{-}$), where nickel (in the form of a complex) is adsorbed onto the surface and eventually undergoes reduction. ${ }^{13}$ From Tafel characterization, the deposition reaction has been observed to occur by transfer of two electrons (slope $=120 \mathrm{mV}$ decade $^{-1}$ ), justifying the reaction mechanism. Other accompanying reactions (hydrogen evolution) may occur depending on the applied potential.

Factors that affect the efficiency of the process such as stirring, occurrence of secondary reactions, disparity in bulk and surface conditions have been studied over the period of time. Since, the process is carried out under acidic conditions $(\mathrm{pH} \sim 2)$, the possibility of a competing hydrogen evolution reaction (HER) also arises. Studies show that reduction of nickel ions occurs at further negative potentials in comparison to electronation of protons, ${ }^{9}$ which makes it critical to lower $\mathrm{H}^{+}$

Table 1 Possible reaction schemes during $\mathrm{Ni}$ electrodeposition process $^{14-17}$
Nickel electrodeposition

$\mathrm{Ni}^{2+}+\mathrm{X}^{-} \rightarrow \mathrm{NiX}^{+}$

$\mathrm{NiX}^{+}+\mathrm{e}^{-} \rightarrow \mathrm{NiX}_{\text {ads }}$

$\mathrm{NiX}_{\text {ads }}+\mathrm{e}^{-} \rightarrow \mathrm{Ni}+\mathrm{X}^{-}$

Nickel hydroxide precipitation

$\mathrm{Ni}^{2+}+2 \mathrm{OH}^{-} \rightarrow \mathrm{Ni}(\mathrm{OH})_{2}$
$\mathrm{H}^{+}+\mathrm{e}^{-} \rightarrow \mathrm{H}_{\text {ads }}$

$\mathrm{H}_{\mathrm{ads}}+\mathrm{H}^{+}+\mathrm{e}^{-} \rightarrow \mathrm{H}_{2}$

$2 \mathrm{H}_{\text {ads }} \rightarrow \mathrm{H}_{2}$

Water oxidation

$2 \mathrm{H}_{2} \mathrm{O} \rightarrow \mathrm{O}_{2}+4 \mathrm{H}^{+}+4 \mathrm{e}^{-}$

$2 \mathrm{H}_{2} \mathrm{O} \rightarrow \mathrm{H}_{2} \mathrm{O}_{2}+2 \mathrm{H}^{+}+2 \mathrm{e}^{-}$
Hydrogen evolution reaction 
reduction either by reducing the adsorption of protons or by using a deposition solution which is relatively less acidic. Reproducibility of nickel deposition results has been reported to be the best in the $\mathrm{pH}$ range of 3.3 to 4.5 , because at further lower $\mathrm{pH}$, significant current is used up in HER, which lowers the current efficiency. As the $\mathrm{H}^{+}$at the surface is consumed, a concentration gradient is developed between the surface and bulk, which results in an increase in the surface $\mathrm{pH}^{18}$ Researchers have proposed the use of boric acid to subdue the HER as well the localized $\mathrm{pH}$ variation. ${ }^{19}$ Uniformity of the deposited nickel is expected to improve in the presence of stirring as it ensures uniform concentration of $\mathrm{H}^{+}$in the vicinity of the wafer.

With hydrofluoric acid as the silicon dioxide etching agent in their contactless bottom-up electrodeposition process for copper, Patterson et al. described an increasing resistance with time in the system eventually leading to total passivation at the voltage limit of their potentiostat. ${ }^{8}$ A similar passivation effect has been observed by Knotter ${ }^{20}$ in his publication on the etching mechanism of silicon dioxide, however this was with n-type doped silicon. Since the silicon samples used in experiments by Patterson et al. were p-type (100) doped it was concluded that porous silicon formation, like that seen by Uhlir ${ }^{21}$ in germanium and silicon electrochemical etching, was a more likely culprit for passivation. In this publication no attempt is made to study the increase in resistance as deposition progresses, but the effect is mitigated by shortening deposition time, increasing potential and current limits, and heating solutions during deposition.

Electrodeposition for metallization is comprised of fairly well understood phenomena, however because the contactless technique used in this publication requires the continuous oxidation of silicon and etching of oxide $^{22}$ to complete the current circuit, the system is much more complex. Previously, ${ }^{\mathbf{8} 23}$ the effect of different solution parameters like temperature, copper sulfate concentration and sulfuric acid concentration on the deposition of copper were investigated. The emphasis of the current work has been on nickel deposition and parameters affecting the process. The first part of the paper discusses in detail about the process of nickel deposition while the second part focusses on the fundamental investigations of the factors affecting the rate of deposition.

\section{Materials and methods}

De-ionized (DI) water of $18 \mathrm{M} \Omega \mathrm{cm}$ resistivity was used in the preparation of solutions and for rinsing of the samples. VLSI grade isopropyl alcohol (99\%) and hydrofluoric acid (49\%) were obtained from Honeywell Inc. Hydrochloric acid (36\%), sodium fluoride $(>99 \%)$ and boric acid $(>99 \%)$ were purchased from Fisher Scientific Inc. Nickel sulfate hexahydrate (99\%) was procured from Sigma Aldrich. The samples used for deposition were p-type $\mathrm{Si}(110)$ wafers $\left(5 \mathrm{e}^{14}-8 \mathrm{e}^{14} \mathrm{~B}\right.$ atoms per $\left.\mathrm{cm}^{3}\right)$, with a $5 \mathrm{~nm}$ titanium adhesion layer and a $500 \mathrm{~nm}$ nickel seed layer on the surface. Nickel plate (99.5\%) with dimensions of $50 \mathrm{~mm} \times$ $50 \mathrm{~mm} \times 6.35 \mathrm{~mm}$ was used as the sacrificial working electrode. Platinum mesh $(99.9 \%)$ of size $50 \times 50 \mathrm{~mm}$ was used as the counter electrode. A power source from B\&K Precision Corporation (current and potential limit of $5 \mathrm{~A}$ and $41 \mathrm{~V}$ ) was used to apply current/potential to the system.

Prior to the experiments, wafer samples and electrodes were cleaned with isopropyl alcohol and $1: 100 \mathrm{HCl}: \mathrm{H}_{2} \mathrm{O}$ (by vol) solution for $1 \mathrm{~min}$ with each step followed by thorough rinsing with DI water. The electrodeposition cell consisted of two chambers separated by a silicon wafer with one chamber containing aqueous 3 or $49 \mathrm{wt} \% \mathrm{HF}$ solution or $1 \mathrm{M}$ sodium fluoride solution ( $\mathrm{pH}$ range 3.0-10.2) as silicon dioxide etchant solution and the other aqueous $0.9 \mathrm{M} \mathrm{NiSO}_{4}$ and $0.5 \mathrm{M} \mathrm{H}_{3} \mathrm{BO}_{3}$ solution $(\mathrm{pH} \sim 4.0)$ as nickel deposition solution. $\mathrm{Si}$ in contact with the etchant solution undergoes a two-step dissolution, the first one being electrochemical oxidation to $\mathrm{SiO}_{2}$ according to reaction (R1) and the second one involves chemical etching of $\mathrm{SiO}_{2}$ as per reaction ( $\mathrm{R} 2)$.

$$
\begin{gathered}
\mathrm{Si}+2 \mathrm{H}_{2} \mathrm{O}=\mathrm{SiO}_{2}+\mathrm{H}_{2}+2 \mathrm{H}^{+}+2 \mathrm{e}^{-} \\
\mathrm{SiO}_{2}+\mathrm{HF}=2 \mathrm{H}^{+}+\mathrm{SiF}_{6}^{2-}+\mathrm{H}_{2} \mathrm{O}
\end{gathered}
$$

The electrons at the silicon/etchant solution interface resulting from first reaction are conducted through the bulk of silicon wafer to be consumed at the interface between Ni layer and aqueous nickel sulfate solution. At this layer interface, Ni ions are reduced and deposited on the surface. Nickel sulfate supplies the nickel ion source while boric acid supports conductivity and dissolution of a sacrificial nickel anode. To maintain overall charge neutrality in the etchant solution, $\mathrm{H}^{+}$ reduction occurs on a Pt mesh cathode immersed in this solution. Further, as the nickel ions are reduced, the deposition solution is depleted of positive charges. The nickel ions are replenished through dissolution from the nickel anode to which a constant potential or current is applied.

About $200 \mathrm{ml}$ of the deposition and etchant solution were used and the effective wafer surface area was about $23 \mathrm{~cm}^{2}$. At the beginning of each experiment, a low rate $\left(5 \mathrm{~mA} \mathrm{~cm}{ }^{-2}\right)$ nickel deposition was performed to obtain a uniform nickel layer $(\sim 1 \mu \mathrm{m})$. Following this, nickel electrodeposition was conducted at higher deposition rates and temperatures $\left(\sim 65^{\circ} \mathrm{C}\right)$ for a period of $1 \mathrm{~h}$. Images of deposited nickel were taken from scanning electron microscope (FEI Inspec-S50) to assess the uniformity of nickel film. For the experiments designed to determine the effect of solution temperature, etchant solution composition and concentration, and stirring, the electrodeposition process was run at maximum achievable current density for $90 \mathrm{~s}$, and the potential was recorded as a function of time. Surface morphology of electrodeposited nickel was characterized by atomic force microscopy (Bruker Multimode 8 AFM, PeakForce Mode). Root mean square (RMS) surface roughness was computed using Bruker NanoScope Analysis 1.5 for each sample. Crystal orientation was evaluated by X-ray diffraction measurements (PANalytical X'Pert Pro, $\mathrm{Cu} \mathrm{K \alpha}$ ) operating at 45 $\mathrm{kV}$ and $40 \mathrm{~mA}$ in the range of $20-100^{\circ}$. Mean grain size for each sample was calculated using the Scherrer calculator in the PANalytical X'Pert Plus software. 


\section{Equilibrium species concentrations for various aqueous fluoride etchants and possible etching mechanism}

Equilibrium concentrations of various fluoride species was evaluated at different temperatures and compositions of etching solution using STABCAL software and the thermodynamic data available in literature. ${ }^{24}$ The etchants under investigation in this work were aqueous solutions of hydrofluoric acid at $\sim 1.5 \mathrm{M}(3 \mathrm{wt} \%)$ and $\sim 25 \mathrm{M}(49 \mathrm{wt} \%)$ and sodium fluoride at $1 \mathrm{M}$. The etching behavior of hydrofluoric acid was compared to sodium fluoride, which supplies $\mathrm{F}^{-}$but is naturally basic. The $\mathrm{pH}$ of the sodium fluoride solutions was adjusted in the range of 3.0-10.2 using $\mathrm{HCl}$ acid to vary the concentration of different fluoride species that etch silicon dioxide at different rates. The probable dissociation/combination reactions occurring in solutions containing fluoride species are given below, ${ }^{20,25}$

$$
\begin{gathered}
\mathrm{HF}=\mathrm{H}^{+}+\mathrm{F}^{-} ; K_{1}=6.85 \times 10^{-4} \mathrm{~mol} \mathrm{l}^{-1} \\
\mathrm{HF}+\mathrm{F}^{-}=\mathrm{HF}_{2}^{-} ; K_{2}=3.9631 \mathrm{~mol}^{-1}
\end{gathered}
$$

$$
2 \mathrm{HF}=\mathrm{H}_{2} \mathrm{~F}_{2} ; K_{3}=2.71 \mathrm{~mol}^{-1}
$$

The release of either nucleophiles $\mathrm{HF}_{2}{ }^{-}$or $\mathrm{H}_{2} \mathrm{~F}_{2}$ is known to significantly affect the etch rate of $\mathrm{SiO}_{2}$, while $\mathrm{HF}$ or $\mathrm{F}^{-}$are not particularly critical. ${ }^{26}$ The equilibrium constants of (R4) and (R5) are greater than 1, indicating that the production of $\mathrm{HF}_{2}{ }^{-}$ and $\mathrm{H}_{2} \mathrm{~F}_{2}$ are favored.

At equilibrium, the concentrations of different dissociated forms of fluoride ( $\mathrm{HF}, \mathrm{H}_{2} \mathrm{~F}_{2}, \mathrm{HF}_{2}{ }^{-}, \mathrm{F}^{-}$) have been plotted as a function of the solution $\mathrm{pH}$ in Fig. 1. At a particular $\mathrm{pH}(\sim 4)$ and solution temperature $\left(25^{\circ} \mathrm{C}\right)$, as the total concentration of $\mathrm{F}$ was increased from 1 to $25 \mathrm{M}$ (Fig. 1(a) to (c)), the relative concentration of the dissociated $\mathrm{HF}_{2}{ }^{-}$increased by almost two times from $40 \%$ to about $75 \%$, while the $\mathrm{H}_{2} \mathrm{~F}_{2}$ concentration was a weaker function of this change. This increase in $\mathrm{HF}_{2}{ }^{-}$concentration was due to the buffering effect provided by the excess $\mathrm{F}^{-}$ ions in the $25 \mathrm{M}$ solution favoring the reaction (R4). It is clear that the effect of $\mathrm{H}_{2} \mathrm{~F}_{2}$ becomes increasingly important only below a $\mathrm{pH}$ of 4 , while $\mathrm{HF}_{2}{ }^{-}$dominates at $\mathrm{pH}$ in the range of 3 to 6 . Another important observation here is that as the $\mathrm{pH}$ is increased beyond 6, all the constituents of the bath dissociate to form $\mathrm{F}^{-}$.
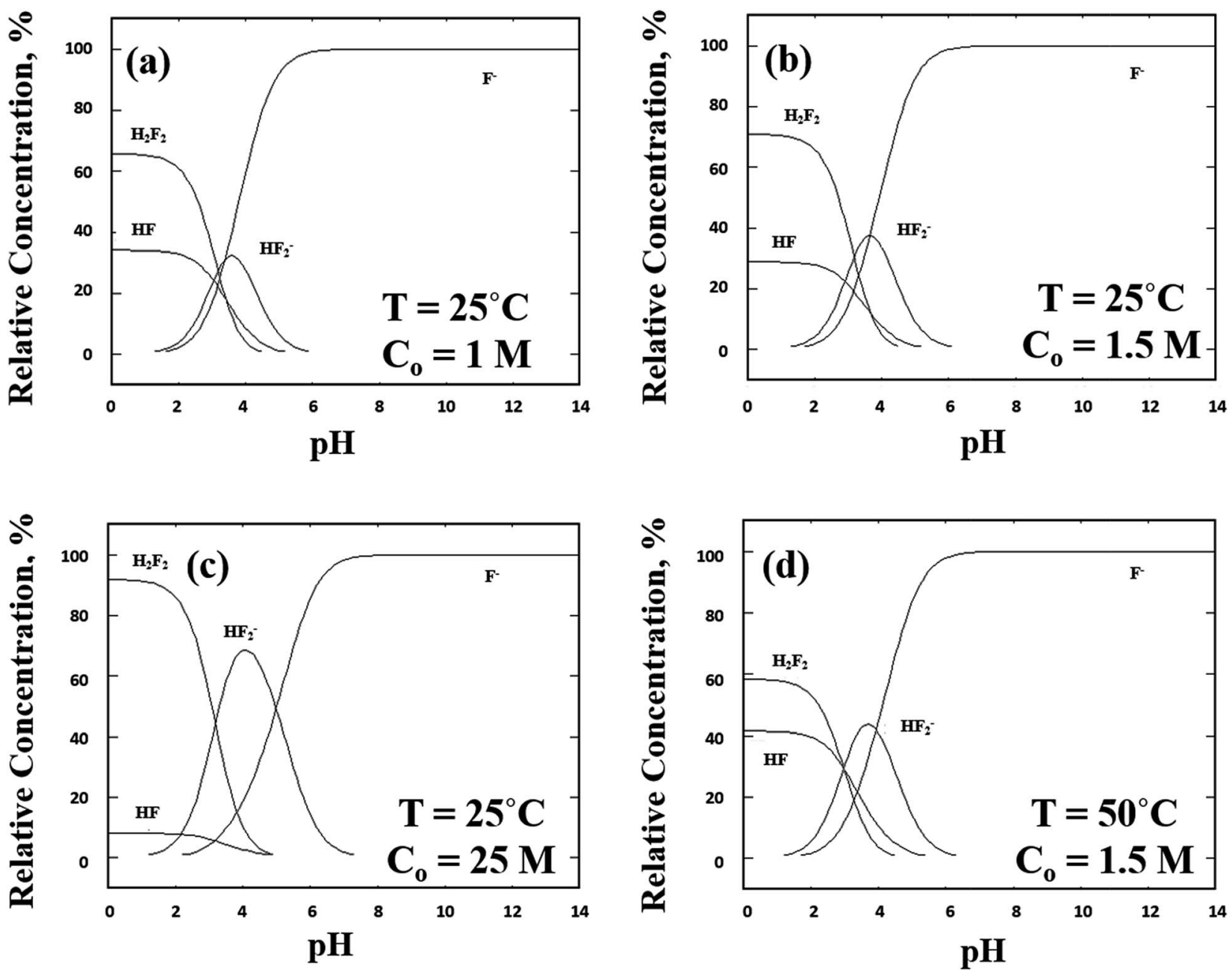

Fig. 1 Equilibrium concentrations of various fluoride species for different concentrations of total $\mathrm{F}$, (a) $1 \mathrm{M}$, (b) $1.5 \mathrm{M}$, (c) $25 \mathrm{M}$ at $25^{\circ} \mathrm{C}$ and (d) $1.5 \mathrm{M}$ at $50{ }^{\circ} \mathrm{C}$. 
The importance of higher alkaline $\mathrm{pH}$ solutions on oxide etching will be discussed in Section 4.3. An increase in solution temperature from 25 to $50{ }^{\circ} \mathrm{C}$ did not realize a notable change in concentrations of either of the $\mathrm{HF}_{2}{ }^{-}$and $\mathrm{H}_{2} \mathrm{~F}_{2}$ indicating a weak dependence of the equilibrium constant on the temperature.

The mechanism of silicon dioxide etching is still a topic of debate. It has been shown, however, by Judge ${ }^{26}$ that fluoride ions alone are poor etching agents. Kikuyama et al. also confirmed that fluoride ions from a highly dissociative salt are only a third as effective at etching as hydrofluoric acid of the same concentration. ${ }^{27}$ The findings of Kikuyama et al. and Judge may imply that complexes of fluoride are the major agents of silicon dioxide etching. Zhang derived an empirical equilibrium equation for $\mathrm{HF}_{2}{ }^{-}$and $\mathrm{H}_{2} \mathrm{~F}_{2}$ complexes in solutions of hydrofluoric acid. ${ }^{22}$ His equations agree with the trends determined by Knotter ${ }^{20}$ that prevalence of $\mathrm{HF}_{2}{ }^{-}$decreases with high acidity and basicity, but that a third reaction path involving dimers of hydrofluoric acid, $\mathrm{H}_{2} \mathrm{~F}_{2}$, are only significant at very high concentration of $\mathrm{HF}$, and consequently low $\mathrm{pH}$.

\section{Results and discussion}

\subsection{Effect of deposition bath composition}

The first step of the study was to evaluate the quality of the deposited nickel layer using a standard deposition bath that consisted of $0.9 \mathrm{M} \mathrm{NiSO}_{4}$ and $0.5 \mathrm{M} \mathrm{H}_{3} \mathrm{BO}_{3}$. As shown in Fig. 2(a) and (d), a conformal layer of nickel was deposited when a current density of about $108 \mathrm{~mA} \mathrm{~cm}^{-2}\left(\sim 2.3 \mu \mathrm{m} \mathrm{min} \mathrm{min}^{-1}\right.$ from theoretical calculations versus $2.2 \mu \mathrm{m} \min ^{-1}$ from mass measurements) was applied through the system. On the contrary, the uniformity of the metal layer was compromised on increasing the current density to about $152 \mathrm{~mA} \mathrm{~cm}{ }^{-2}$ (3.1 $\mu \mathrm{m} \mathrm{min}{ }^{-1}$ from theoretical calculations versus $3.0 \mu \mathrm{m} \mathrm{min}{ }^{-1}$ from mass measurements). Fig. 2(e) indicates significant microroughness on the surface, which could be attributed to the simultaneous generation of $\mathrm{H}_{2}$ at higher current densities. ${ }^{28}$ Due to the depletion of $\mathrm{H}^{+}$in the vicinity of the surface, the $\mathrm{pH}$ may become relatively higher $(>9)$ at the surface, which eventually could lead to the formation of insoluble precipitate $\mathrm{Ni}(\mathrm{OH})_{2} \cdot{ }^{29}$ The formation of the precipitate could result in poor adhesion of subsequent nickel layers deposited and may lead to their peeling off causing localized roughness.

In addition to poor uniformity at higher current transients, another issue encountered was significant generation of bubbles at the nickel anode. These bubbles were likely oxygen bubbles and generated due to oxidation of water under high anodic potentials. Secondary reactions can negatively affect the process efficiency and bubbles in the solution can stick on surfaces and induce non-uniformity in deposition. In order to resolve this issue, the use of chloride ions $\left(\mathrm{Cl}^{-}\right)$as an additive was investigated, as $\mathrm{Cl}^{-}$is known to increase the ease of dissolution of nickel through improved anode corrosion. ${ }^{30}$ It was visually observed that the generation of bubbles was significantly reduced on the addition of $0.2 \mathrm{M} \mathrm{Cl}^{-}$but as can be seen from Fig. 2(f), the deposited layer had poor topographical characteristics and will not suffice the demands of conformality required for deposition in through silicon vias.

\subsection{Microstructural characterization}

The microstructural properties such as surface roughness, crystal orientation and grain size were characterized by AFM and XRD measurements. As shown in Fig. 3(a) through (c), the nickel film deposited at $108 \mathrm{~mA} \mathrm{~cm}{ }^{-2}$ from $\mathrm{Cl}^{-}$free Watts solution exhibited the best surface uniformity with RMS roughness value of $282 \pm 22 \mathrm{~nm}$. Increasing the current density from 108 to $152 \mathrm{~mA} \mathrm{~cm}^{-2}$ increased the RMS roughness to 402 $\pm 3 \mathrm{~nm}$. Further, the addition of $0.2 \mathrm{M}$ chloride significantly increases the mean surface roughness by about 2 times to $803 \pm$ $150 \mathrm{~nm}$. These results correlate well to those observed from SEM imaging.

The effect of chloride ion on the increase in RMS values can be explained by two aspects: (1) localized corrosion by $\mathrm{Cl}^{-}$and (2) electrolyte diffusion. Although addition of chloride can help improve the dissolution of nickel from the anode, it also causes localized corrosion on deposited nickel film, ${ }^{31}$ leading to surface irregularities. The diffusion of $\mathrm{Ni}$ ions in the electrolyte during electrodeposition enhances these surface irregularities rather than damp them..$^{32}$ During the deposition process, nickel ion concentration is higher near the tip of irregularity (caused by localized corrosion), where the thickness of the diffusion layer is smaller, thereby allowing greater diffusion flux and ultimately resulting in higher deposition rates in those areas and preferential plating. Thus diffusion can cause more rapid growth of peaks than valleys, and increase the surface roughness. ${ }^{33}$

Fig. 4 shows the intensity of diffraction peaks for electrodeposited nickel films as a function of angle of diffraction $(2 \theta)$. It is evident that both current density and composition of the bath have an impact on the crystalline nature/orientation of the nickel grains. In the absence of any added $\mathrm{Cl}^{-}$, a distinct peak at $76.4^{\circ}$ pertaining to the (220) plane was observed while $\mathrm{Cl}^{-}$ containing formulations exhibited a peak at $51.8^{\circ}$ corresponding to the (200) plane. This is an interesting result as it signifies the importance of solution formulation on the orientation of the deposited metal. In the past, researchers ${ }^{32,34}$ have conducted morphological characterization of electrodeposited crystalline nickel films from Watts bath $\left(\mathrm{NiSO}_{4}+\mathrm{NiCl}_{2}+\mathrm{H}_{3} \mathrm{BO}_{3}\right)$. Under an applied current density of $100 \mathrm{~mA} \mathrm{~cm}{ }^{-2}$, nickel films were oriented either in the (111) or (200) plane which is in contrast to the results observed with our process. Table 2 compares the intensities of (200) and (220) peaks for different current densities and chemical formulations. In solutions containing $\mathrm{NiSO}_{4}$ and $\mathrm{H}_{3} \mathrm{BO}_{3}$, an increase in current density, decreased the relative intensity of $(220) /(200)$ peak by about 1.6 times. Nickel film texture and orientation are known to depend on the hydrogen coverage on the substrate. ${ }^{32}$ As the deposition current density increases from 108 to $152 \mathrm{~mA} \mathrm{~cm}^{-2}$, the rate of $\mathrm{H}_{2}$ evolution also increases from HER. Since the localized concentration of $\mathrm{H}_{2}$ increased, the formation of (200) surface was favored which is in agreement with the trends observed in literature. ${ }^{32,35}$

Mean grain size of deposited films was calculated using the XRD data and is tabulated in Table 2. Increasing the current density from 108 to $152 \mathrm{~mA} \mathrm{~cm}^{-2}$ for chloride-free based deposition solutions, increased the average grain size slightly 

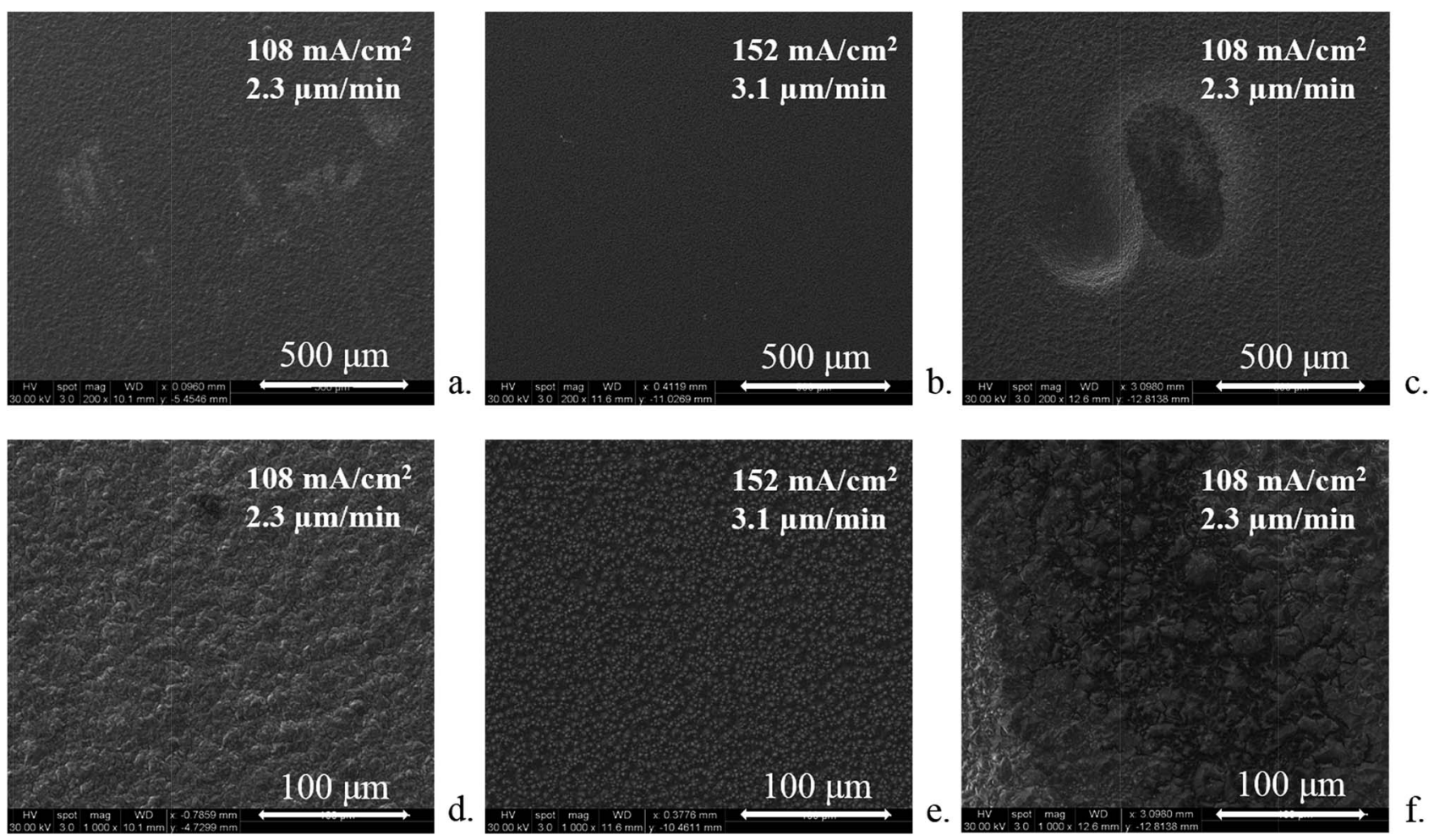

Fig. 2 SEM images of electrodeposited nickel at $200 \times$ (a), (b) and (c) and $1000 \times$ (d), (e) and (f). Deposition bath composition for (a), (b), (d) and (e) was $0.9 \mathrm{M} \mathrm{NiSO}_{4}$ and $0.5 \mathrm{M} \mathrm{H}_{3} \mathrm{BO}_{3}$ and for (c) and (f) was $0.2 \mathrm{M} \mathrm{NiCl}_{2}, 0.9 \mathrm{M} \mathrm{NiSO}_{4}$ and $0.5 \mathrm{M} \mathrm{H}_{3} \mathrm{BO}_{3}$.

from 96 to $105 \mathrm{~nm}$. The grain formation was a weak function of the applied current density, while varying significantly with the added anion. In $\mathrm{NiSO}_{4}$ and $\mathrm{H}_{3} \mathrm{BO}_{3}$ solutions, the grain size was about $100 \mathrm{~nm}$ whereas addition of $\mathrm{Cl}^{-}$increased it to greater than $150 \mathrm{~nm}$. These numbers are relatively larger than those reported in the literature $(<50 \mathrm{~nm}) .^{32,36,37}$ In the case of Watts bath as the deposition solution, the line width broadening of characteristic peaks in the spectrum was not enough for a reliable calculation indicating even greater mean grain size $(>150 \mathrm{~nm})$ for those samples.

\subsection{Effect of solution temperature and concentration of etchant}

The effect of solution temperature was examined by measuring the potential between the anode and the cathode required to induce maximum current density (within the limits of the power supply) at different temperatures of etchant and deposition solutions. Both etchant and deposition solutions were heated simultaneously. It can be noticed from Fig. 5(a) that the effect is fairly linear at lower solutions concentrations of $3 \%$ $\mathrm{HF}$ and $1 \mathrm{M}$ sodium fluoride. In both of these cases, the potential value reached the maximum limit of the power supply and the current was monitored. In the case of high concentration of $\mathrm{HF}(49 \%)$ solution, the maximum current density reached the limit of the power supply but the potential did not and was measured with time. At this HF concentration, the benefit of adding heat was less than linear, tapering towards higher temperatures. Current can be seen as a representation of reaction rate since current can only pass through the system by satisfying reactions on both etchant ( $\mathrm{Si}$ oxidation and $\mathrm{SiO}_{2}$ etching) and deposition (Ni deposition) sides. From Arrhenius theory, it is a known fact that the reaction kinetics increase with increase in temperature. Although sodium fluoride facilitates a lower peak current at all temperatures, the effect is seen to be roughly equivalent between $3 \% \mathrm{HF}$ and $1 \mathrm{M} \mathrm{NaF}$ as the slopes of the curves (current density vs. temperature) were similar. The similarity of the trends suggests that the same mechanism is dominant in both cases despite the difference in acidity, ranging from approximately pH 3 (3\% HF) to 10 (1 M $\mathrm{NaF}$ ). The HF solution provides a better silicon dioxide etch rate due to higher concentrations of difluoride species than the alkaline $\mathrm{pH}$ sodium fluoride solution (where $\mathrm{F}^{-}$dominates) allowing faster regeneration of silicon surface for its subsequent oxidation. As temperature increased, the necessary potential for said current decreased. The maximum achievable current density for any temperature condition was higher for $49 \% \mathrm{HF}$ compared to $3 \% \mathrm{HF}$ or $1 \mathrm{M} \mathrm{NaF}$ re-emphasizing the importance of silicon dioxide etching in achieving higher nickel deposition rates. In an earlier publication on this contactless deposition technique, increasing the concentration of hydrofluoric acid above 3\% did not increase current flow at any given overpotential. ${ }^{8}$ However, in this study, current was found to increase substantially between 3 and $49 \% \mathrm{HF}$ at all temperatures. The temperatures of solutions as well as the deposition solution composition are different for the experiments reported in this work, but the doping of the silicon substrate and composition of the etching solution are the same. 

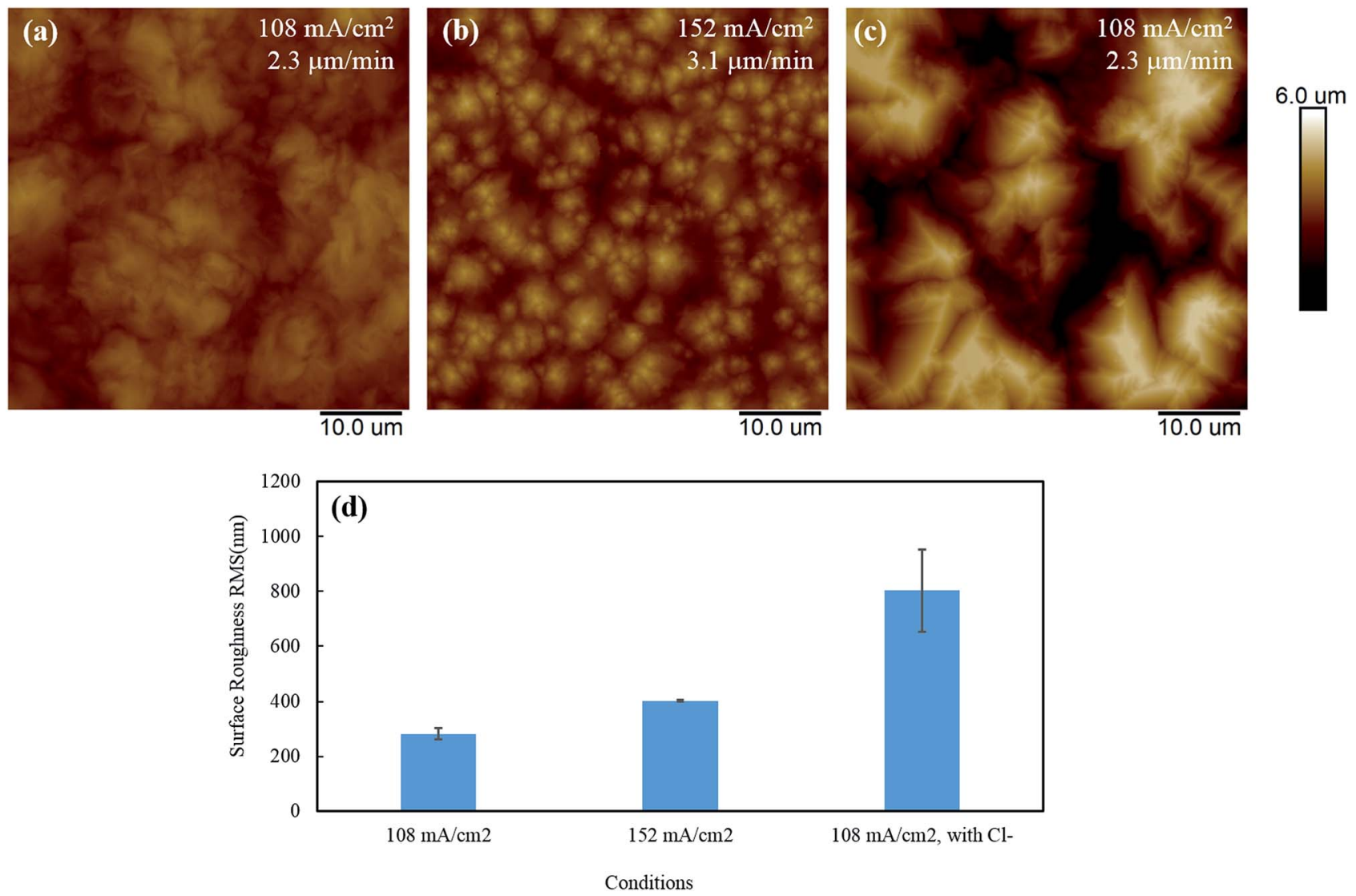

Fig. 3 AFM images of electrodeposited nickel (a), (b) and (c), and surface roughness as a function of current density and composition of deposition bath (d). Deposition bath composition, (a) and (b) $0.9 \mathrm{M} \mathrm{NiSO}_{4}$ and $0.5 \mathrm{M} \mathrm{H}_{3} \mathrm{BO}_{3}$ and (c) $0.2 \mathrm{M} \mathrm{NiCl}_{2}, 0.9 \mathrm{M} \mathrm{NiSO}_{4}$ and $0.5 \mathrm{M} \mathrm{H}_{3} \mathrm{BO}_{3}$. Scan rate: $0.930 \mathrm{~Hz}$. Color scale: 0-6 $\mu \mathrm{m}$.

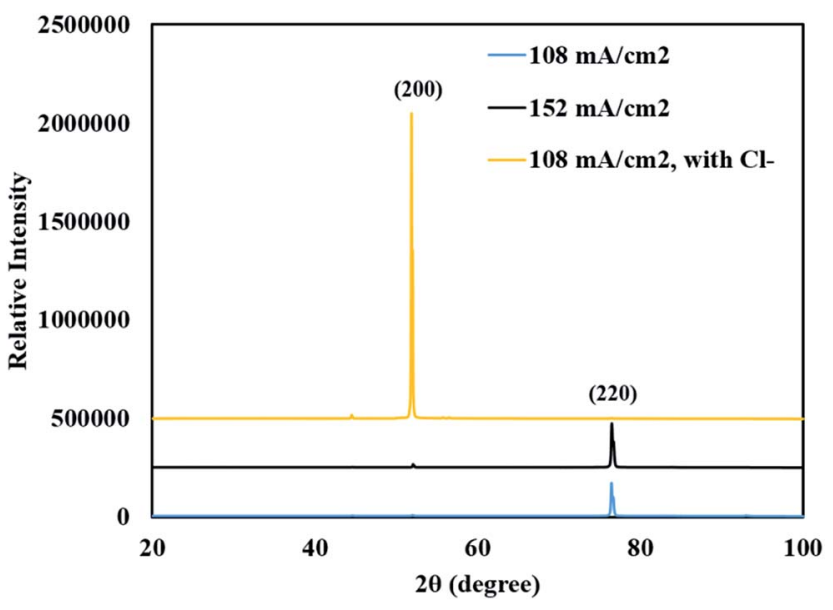

Fig. $4 \mathrm{X}$-ray diffraction spectrum of nickel films electrodeposited at 108 and $152 \mathrm{~mA} \mathrm{~cm}^{-2}$ using $0.9 \mathrm{M} \mathrm{NiSO}_{4}+0.5 \mathrm{M} \mathrm{H}_{3} \mathrm{BO}_{3}$, and 108 $\mathrm{mA} \mathrm{cm}{ }^{-2}$ using Watts bath $\left(0.9 \mathrm{M} \mathrm{NiSO}_{4}+0.5 \mathrm{M} \mathrm{H}_{3} \mathrm{BO}_{3}+0.2 \mathrm{M} \mathrm{NiCl}_{2}\right)$.

At room temperature it can be seen that $49 \%$ HF etching solution achieves nearly double the current density, 220 $\mathrm{mA} \mathrm{cm}{ }^{-2}$ vs. $115 \mathrm{~mA} \mathrm{~cm}^{-2}$, at about half the potential, $21 \mathrm{~V} v s$. $41 \mathrm{~V}$, of the $3 \% \mathrm{HF}$ solution. The $3 \%$ solution benefited more from the addition of heat. Heating from 20 to $60{ }^{\circ} \mathrm{C}$ reduced the
Table 2 Relative intensity of diffraction peaks with respect to different orientation planes and average grain size

\begin{tabular}{llll}
\hline Bath composition & $\begin{array}{l}I \\
\left(\mathrm{~mA} \mathrm{~cm}{ }^{-2}\right)\end{array}$ & $\begin{array}{l}I_{\mathrm{R}} \\
(220) /(200)\end{array}$ & $\begin{array}{l}\text { Average grain size } \\
(\mathrm{nm})\end{array}$ \\
\hline $\mathrm{NiSO}_{4}+\mathrm{H}_{3} \mathrm{BO}_{3}$ & 108 & 86.928 & 96 \\
$\mathrm{NiSO}_{4}+\mathrm{H}_{3} \mathrm{BO}_{3}$ & 152 & 52.585 & 105 \\
$\mathrm{NiSO}_{4}+\mathrm{H}_{3} \mathrm{BO}_{3}+\mathrm{Cl}^{-}$ & 108 & 0.005 & $>150$
\end{tabular}

resistance of the system by approximately $40 \%$, while the same temperature increase in the $49 \% \mathrm{HF}$ experiment only lowered system resistance by about $25 \%$. However, system resistance for $49 \% \mathrm{HF}$ solution at room temp was far less than the resistance for $3 \%$ even at the highest temperature, $60{ }^{\circ} \mathrm{C}$, showing that the increase in hydrofluoric acid concentration does indeed increase current capacity of the system at a given potential. This may imply that the temperature increase does more to augment etching of silicon dioxide, which is a purely chemical process, than oxidation of silicon, which is electrochemically promoted. The oxidizing agent, water, is in excess in the $3 \%$ HF case but of comparable concentration to $\mathrm{HF}$ in the $49 \%$ case. Both $3 \% \mathrm{HF}$ and $\mathrm{NaF}$ had a linear response to temperature increase. Therefore it may be that at highest concentrations of HF and within the potential range of these experiments the oxidation of 

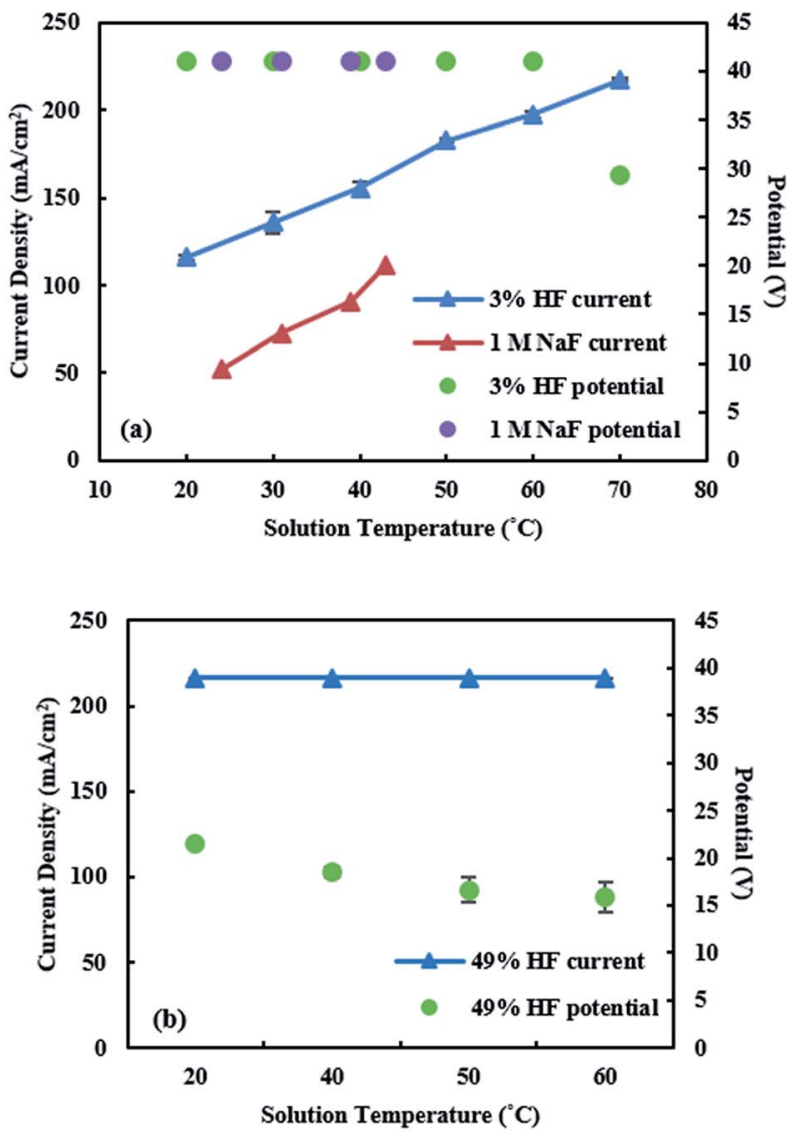

Fig. 5 Current density and potential versus temperature curves for (a) $3 \% \mathrm{HF}$ and $1 \mathrm{M} \mathrm{NaF}$ as etchant solutions and (b) $49 \% \mathrm{HF}$ as etchant solution. Deposition bath composition was $0.9 \mathrm{M} \mathrm{NiSO}_{4}$ and $0.5 \mathrm{M}$ $\mathrm{H}_{3} \mathrm{BO}_{3}$.

silicon takes a rate limiting role and lowers equilibrium current from linearly predicted values.

\subsection{Effect of stirring}

The stirring of electrolyte solution is commonly employed to maintain the uniform concentration and circumvent the local temperature rises in the bath. ${ }^{38}$ Here, the experiments were designed to understand the importance of mass transfer in each of the solutions for the deposition process. Fig. 6 shows the comparison of current densities with and without stirring for either deposition or etchant solution at two different temperatures $\left(25\right.$ and $\left.45{ }^{\circ} \mathrm{C}\right)$. At room temperature $\left(25^{\circ} \mathrm{C}\right)$, as the deposition solution was stirred, there was insignificant increase observed in the current density (from 102 (no stirring) to $107 \mathrm{~mA} \mathrm{~cm}{ }^{-2}$ ). This suggests that at lower temperature, the deposition solution is reaction rate controlled and an increase in mass transfer rate of $\mathrm{Ni}^{2+}$ can hardly improve the deposition rate. As the temperature was increased to $45^{\circ} \mathrm{C}$, the stirring process increases the current density from 160 (no stirring) to $182 \mathrm{~mA} \mathrm{~cm}^{-2}$, showing an obvious change compared to that observed at room temperature. This phenomenon indicates that for higher temperature, the reaction rate becomes faster according to Arrhenius equation, and the diffusion rate is

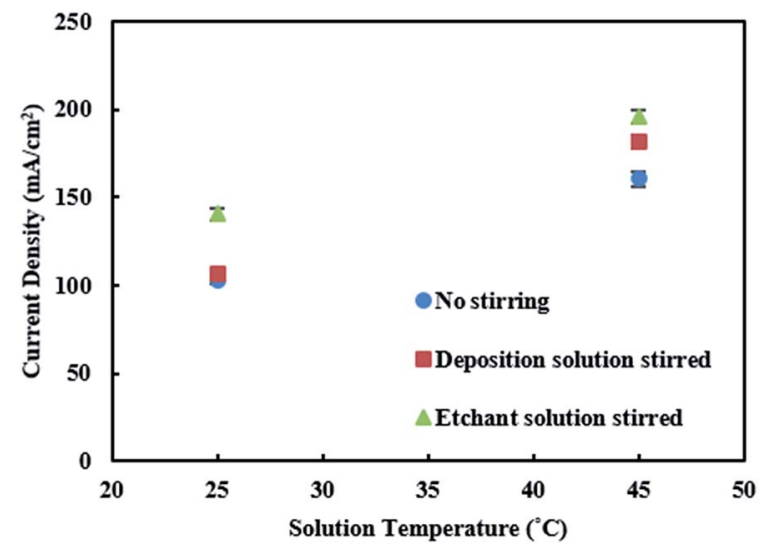

Fig. 6 Effect of stirring of deposition or etching solution on current density at two different solution temperatures (0.9 M nickel sulfate with $0.5 \mathrm{M}$ boric acid as deposition solution and $3 \% \mathrm{HF}$ as etchant solution).

relatively slower and cannot transport sufficient $\mathrm{Ni}$ ions to keep up with the deposition reaction rate at the surface, suggesting that the deposition process becomes mass transfer controlled at this temperature.

Stirring of the etchant solution increases the current density from $102 \mathrm{~mA} \mathrm{~cm}^{-2}$ to $141 \mathrm{~mA} \mathrm{~cm}{ }^{-2}$ at room temperature and $160 \mathrm{~mA} \mathrm{~cm}{ }^{-2}$ to $196 \mathrm{~mA} \mathrm{~cm}{ }^{-2}$ at $45{ }^{\circ} \mathrm{C}$, and achieves much greater system current density, than that with stirring of deposition solution. At a particular temperature, mechanical stirring enhances the total flux of reactants and increases the availability of water molecules for silicon oxidation or fluoride species for silicon dioxide etching. Based on these results, it is clear that oxidation and etching reactions, not the metal diffusion, control the overall current density for Ni deposition rates.

\subsection{Effect of etchant composition}

Fluoride based (HF, buffered HF) or alkaline (KOH, NaOH) solutions have widely been used in the semiconductor industry for etching of $\mathrm{SiO}_{2}$ as they form soluble complexes. The mechanisms of these chemistries are well explained in literature but there is a lack of understanding of the effect of salt solutions (e.g. $\mathrm{NaF}, \mathrm{NH}_{4} \mathrm{~F}$ ) on oxide etching. Previously, it has been shown that $\mathrm{HF}_{2}{ }^{-}$is critical for $\mathrm{SiO}_{2}$ etching at $\mathrm{pH}$ below $7 .{ }^{26}$ We investigate the effect of different fluorine species on oxide etch rate through measurement of maximum achievable current density in sodium fluoride solution of varying $\mathrm{pH}$ at room temperature. When $1 \mathrm{M}$ $\mathrm{NaF}$ solution (natural $\mathrm{pH} \sim 10$ ) was used as the etchant, a maximum current density of about $90 \mathrm{~mA} \mathrm{~cm} \mathrm{~cm}^{-2}$ was achieved (Fig. 7). The dissolution of oxide at this alkaline $\mathrm{pH}$ occurs mainly due to the reaction with $\mathrm{OH}^{-}$present at a concentration of $\sim 0.1 \mathrm{mM}$. All of the fluoride species is expected to be present in the form of $\mathrm{F}^{-}$at a $\mathrm{pH}$ of 10 . As the solution was acidified to a $\mathrm{pH}$ of about 6.2 , by adding $\mathrm{HCl}$, the current density remained almost constant. It is unclear as to why the current density does not change with decrease in $\mathrm{pH}$ even though the $\mathrm{OH}^{-}$concentration decreases to $10^{-8} \mathrm{M}$ and concentration of $\mathrm{F}^{-}$is unchanged. Beyond this point, even a slight decrease in $\mathrm{pH}$ (to 


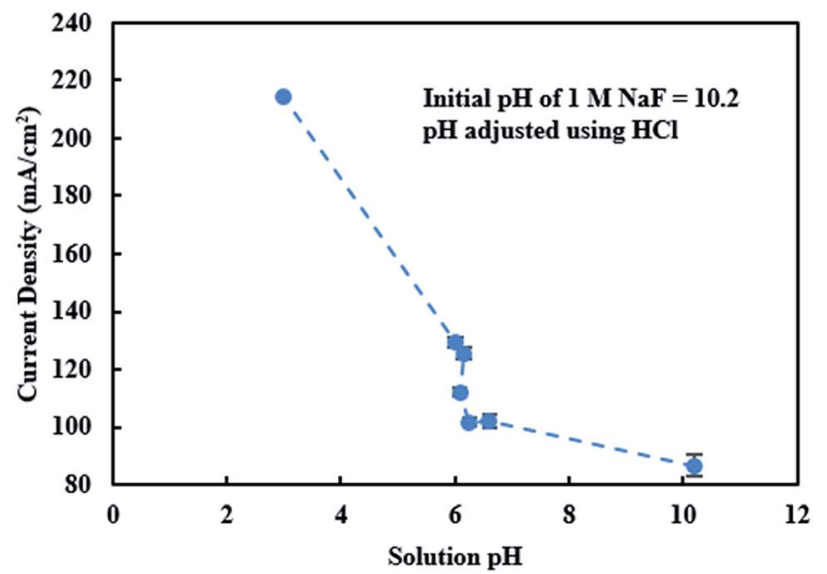

Fig. 7 Effect of $\mathrm{pH}$ of sodium fluoride solution (1 M) on maximum current density.

6.0) increased the current density from 90 to $130 \mathrm{~mA} \mathrm{~cm}^{-2}$. This sharp increase in the current density was attributed to the onset of generation of $\mathrm{HF}_{2}{ }^{-}$, which, although low (Fig. 1(a)) in concentration, seems to be critical. Further lowering of the $\mathrm{pH}$ to about 3.0 achieved a maximum current density of about $220 \mathrm{~mA}$ $\mathrm{cm}^{-2}$. Judge reports that the etch rate of $\mathrm{SiO}_{2}$ in $\mathrm{NH}_{4} \mathrm{~F}$ solutions varies as a function of $\mathrm{HF}_{2}{ }^{-}$or $\mathrm{HF}$ concentration which in turn depends on the solution $\mathrm{pH}^{26}$ Maximum etch rate $\left(0.2 \mathrm{~nm} \mathrm{~s}^{-1}\right)$ of $\mathrm{SiO}_{2}$ was observed at a $\mathrm{pH}$ of $\sim 3$ and attributed to the greater concentration of $\mathrm{HF}_{2}^{-}$. It was shown that both etch rate and $\left[\mathrm{HF}_{2}{ }^{-}\right]$drop by about 4 times as the $\mathrm{pH}$ increases from 3 to $\sim 4.5$. From our equilibrium calculation results displayed in Fig. 1, it can be noticed that at solution $\mathrm{pH}$ of 3 , concentrations of $\mathrm{HF}_{2}{ }^{-}$ and $\mathrm{H}_{2} \mathrm{~F}_{2}$ were significant higher compared to those at $\mathrm{pH} 6$. This implies that the presence of difluoride species is critical for achieving higher oxide etch rates, which results in higher maximum current density and therefore greater metal deposition rates in our process.

\section{Conclusions}

We have successfully shown that using a contactless technique, a conformal deposition of nickel at rates as high as 2.3 $\mu \mathrm{m} \mathrm{min}^{-1}$ can be achieved. Increasing the deposition rates (to $3.1 \mu \mathrm{m} \mathrm{min}{ }^{-1}$ ) or addition of $\mathrm{Cl}^{-}$to the $\mathrm{NiSO}_{4} / \mathrm{H}_{3} \mathrm{BO}_{3}$ deposition bath adversely affected the topographical characteristics of the $\mathrm{Ni}$ surface. Investigations of microstructural properties of $\mathrm{Ni}$ films deposited using chloride-free solutions revealed higher surface roughness $(>200 \mathrm{~nm})$, larger grain size $(\sim 100 \mathrm{~nm})$ and crystal orientation favoring the (220) plane. Therefore, solution variables such as temperature and agitation of electrolyte along with current pulsing will be examined in the near future to reduce roughness and grain size, while maintaining high deposition rates.

Comparisons of the effect of concentration of the etchant solution indicated that solutions with higher total F (49\% HF) attained current densities as high as $220 \mathrm{~mA} \mathrm{~cm}$ at room $^{-2}$ temperature $\left(20^{\circ} \mathrm{C}\right)$, while a $3 \% \mathrm{HF}$ solution exhibited only about $115 \mathrm{~mA} \mathrm{~cm} \mathrm{~cm}^{-2}$ implying the importance of etching of silicon dioxide in regenerating the silicon surface for achieving higher deposition rates. Further, the temperature effect was more critical for the lower concentration etchant solutions (3\% $\mathrm{HF}$ or $1 \mathrm{M} \mathrm{NaF}$ ) and showed a linear increase in current density with solution temperature. Current densities as high as $50 \mathrm{~mA} \mathrm{~cm}{ }^{-2}$ were achieved in the presence of $1 \mathrm{M} \mathrm{NaF}$ solution at room temperature. Although the current densities in the presence of $3 \% \mathrm{HF}$ solution were about two times that in $\mathrm{NaF}$ solution, it still gives a reason to explore the use of $\mathrm{NaF}$ solution, which can serve as an alternative oxide etching solution for this contactless process. At room temperature, acidifying the $\mathrm{NaF}$ solution by adding $\mathrm{HCl}$ revealed that at $\mathrm{pH}$ lower than 6.1 there is a rapid increase in current density and becomes maximum $\left(220 \mathrm{~mA} \mathrm{~cm}^{-2}\right)$ at a pH of 3 in the investigated $\mathrm{pH}$ range of 3-10. Stirring of the etchant solution realized about $30 \%$ higher current density at a given temperature indicating oxidation of silicon and etching of oxide as limiting steps in the overall deposition process.

\section{Acknowledgements}

The authors would like to acknowledge Applied Materials Inc. (gift account \# 5510810) and Semiconductor Research Corporation for Environmentally Benign Semiconductor Manufacturing (account \# SRC 425.036) for financially supporting the project.

\section{Notes and references}

1 K. Kondo, N. Yamakawa, Z. Tanaka and K. Hayashi, J. Electroanal. Chem., 2003, 559, 137-142.

2 R. Beica, C. Sharbono and T. Ritzdorf, Proceedings of Electronic Components and Technology Conference, Orlando, 2008, pp. 577-583.

3 J. H. Lau, Microelectron. Int., 2011, 28(2), 8-22.

4 S. C. Hong, W. G. Lee, W. J. Kim, J. H. Kim and J. P. Jung, Microelectron. Reliab., 2011, 51, 2228-2235.

5 P. C. Andricacos, Electrochem. Soc. Interface, 1999, 8, 32-37.

6 T. Defforge, J. Billoue, M. Diatta, F. Tran-Van and G. Gautier, Nanoscale Res. Lett., 2012, 7, 1-7.

7 G. A. Di Bari, in Modern Electroplating, ed. M. Schlesinger and M. Paunovic, John Wiley \& Sons, 5th edn, 2010, ch. 3, pp. 7983.

8 Z. Patterson, C. Weber, R. Balachandran, R. Gouk, S. Verhaverbeke and M. Keswani, ECS Electrochem. Lett., 2014, 3(10), D41-D43.

9 E. Gomez, R. Pollina and E. Valles, J. Electroanal. Chem., 1995, 386, 45-56.

10 R. Orinakova, A. Turonova, D. Kladekova, M. Galova and R. M. Smith, J. Appl. Electrochem., 2006, 36, 957-972.

11 R. C. V. Piatti, A. J. Arvia and J. J. Podesta, Electrochim. Acta, 1969, 14, 541-560.

12 A. Saraby-Reintjes and M. Fleischmann, Electrochim. Acta, 1984, $20(4), 557-566$.

13 E. Chassaing, M. Joussellin and R. Wiart, J. Electroanal. Chem., 1983, 157, 75-88. 
14 I. Epelboin, M. Joussellin and R. Wiart, J. Electroanal. Chem., 1981, 119, 61-71.

15 M. E. G. Lyons, A. Cakara, P. O'Brien, I. Godwin and R. L. Doyle, Int. J. Electrochem. Sci., 2012, 7, 11768-11795.

16 J. B. Gerken, J. G. McAlpin, J. Y. C. Chen, M. L. Rigsby, W. H. Casey, R. D. Britt and S. S. Stahl, J. Am. Chem. Soc., 2011, 133, 14431-14442.

17 P. Drogui, S. Elmaneh, M. Rumeau, C. Bernard and A. Rambaud, J. Appl. Electrochem., 2001, 31(8), 877-882.

18 J. Ji, C. Cooper, D. B. Dreisinger and E. Peters, J. Appl. Electrochem., 1995, 25, 642-650.

19 M. Supicova, R. Rozik, L. Trnkova, R. Orinakova and M. Galova, J. Solid State Electrochem., 2006, 10, 61-68.

20 D. M. Knotter, J. Am. Chem. Soc., 2000, 122(18), 4345-4351. 21 A. Uhlir Jr, Bell Syst. Tech. J., 1956, 35(2), 333-347.

22 X. G. Zhang, in Electrochemistry of Silicon and its Oxide, Kluwer Academic Publishers, New York, 2001, ch. 4, pp. 155-163.

23 C. Weber, Z. Patterson, M. Zhao, R. Balachandran, R. Gouk, S. Verhaverbeke, F. Shadman and M. Keswani, Mater. Sci. Semicond. Process., 2015, 30, 578-584.

24 R. Govindarajan, M. Keswani and S. Raghavan, Mater. Sci. Semicond. Process., 2014, 27, 390-396.

25 J. Buhler, F.-P. Steiner and H. Baltes, J. Micromech. Microeng., 1997, 7, R1-R13.

26 J. S. Judge, J. Electrochem. Soc., 1971, 118(11), 1772-1775.
27 H. Kikuyama, M. Waki, M. Miyashita, T. Yabune, N. Miki, J. Takano and T. Ohmi, J. Electrochem. Soc., 1994, 141(2), 366-374.

28 D. J. Macnaughtan and A. W. Hothersall, Trans. Faraday Soc., 1928, 24, 497-509.

29 E. Protopopoff and P. Marcus, in ASM Handbook: Corrosion: Fundamentals, Testing, and Protection, ASM International, Novelty, 2003, vol. 13, p. 17.

30 A. Vignes, in Extractive Metallurgy 2: Metallurgical Reaction Processes, ISTE Ltd. and John Wiley Sons Inc., Hoboken, 2011, ch. 2, pp. 87-116.

31 B. MacDougall, J. Electrochem. Soc., 1979, 126(6), 919-925.

32 F. Nasirpouri, M. R. Sanaeian, A. S. Samardak, E. V. Sukovatitsina, A. V. Ognev, L. A. Chebotkevich, M. G. Hosseini and M. Abdolmaleki, Appl. Surf. Sci., 2014, 292, 795-805.

33 D. Landolt and A. Marlot, Surf. Coat. Technol., 2003, 170, 813.

34 T. Borkar and S. P. Harimkar, Surf. Coat. Technol., 2011, 205, 4124-4134.

35 D. E. Rusu, A. Ispas, A. Bund, C. Gheorghies and G. Carac, J. Coat. Technol. Res., 2012, 9(1), 87-95.

36 A. M. Rashidi and A. Amadeh, J. Mater. Sci. Technol., 2010, 26(1), 82-86.

37 D. H. Jeong, F. Gonzalez, G. Palumbo, K. T. Aust and U. Erb, Scr. Mater., 2001, 44, 493-499.

38 A. Ashok and P. Pal, Sci. World J., 2014, 2014, 1-9. 